\title{
Crystal Growth and Characterization of the Rare-earth Orthoferrite $\mathrm{Sm}_{0.8} \mathrm{~Tb}_{0.2} \mathrm{FeO}_{3}$ Single Crystal
}

\author{
ZHAO Xiang-Yang ${ }^{1}$, MAN Pei-Wen ${ }^{1}$, XIE Tao $^{2}$, WU An-Hua ${ }^{1}$, SU Liang-Bi ${ }^{1}$ \\ (1. Shanghai Institute of Ceramics, Chinese Academy of Sciences, Shanghai 200050, China; 2. School of Materials Science and En- \\ gineering, Shanghai Institute of Technology, Shanghai 200235, China)
}

\begin{abstract}
Sm}_{0.8} \mathrm{~Tb}_{0.2} \mathrm{FeO}_{3}$ single crystal was grown by the floating zone method. Laue back reflection was used to check the crystal's quality and orientation. The temperature dependence of the magnetization under ZFC process was measured in an external field $500 \mathrm{Oe}$ along $c$-axis. A clear spin reorientation is observed in the range of 360-400 K. Considering the recent report that the spin reorientation transition temperature of $\mathrm{Sm}_{1-x} \mathrm{~Tb}_{x} \mathrm{FeO}_{3}$ is linear decreased with the increase of $\mathrm{Tb}$ ions content, the present data reveals the changed $\mathrm{Fe}^{3+}-\mathrm{Re}^{3+}$ super-exchange interaction. The curve of temperature dependence of thermal expansion exhibits three phase transitions at about $250 \mathrm{~K}, 350-480 \mathrm{~K}$, and $700 \mathrm{~K}$, respectively. The abnormal phase transition observed at $250 \mathrm{~K}$ may be resulted from the change of rare earth ions moment orientation polarized by $\mathrm{Fe}^{3+}$ sub-lattice net moment. The spin reorientation transition takes place in a temperature range from $350 \mathrm{~K}$ to $480 \mathrm{~K}$. The iron spins transform from antiferromagnetic ordered arrangement to paramagnetic disordered arrangement at $\sim 700 \mathrm{~K}$.
\end{abstract}

Key words: orthoferrites; floating zone method; phase transitions

The rare-earth orthoferrites $\mathrm{ReFeO}_{3}(\mathrm{Re}=$ rare-earth) crystallise in an orthorhombic distorted perovskite structure is belonging to the Pbnm space group ${ }^{[1]}$. Recently, $\mathrm{ReFeO}_{3}$ have been investigated for their novel properties, such as multiferroicity ${ }^{[2-5]}$, ultrafast inverse opto-magnetic effect $^{[6]}$, laser-induced spin-reorientation phase transition switching ${ }^{[7]}$. The magnetic moments of iron and rare earth atoms as well as the interactions between them are the source of the magnetic properties of these orthoferrites. It is common to divide all interactions into Re-Re, $\mathrm{Fe}-\mathrm{Fe}$ and $\mathrm{Fe}-\mathrm{Re}$ ones. The strongest interaction is the isotropic superexchange interaction between $\mathrm{Fe}^{3+}$. Below the Néel temperature $T_{\mathrm{N}} \approx 670 \mathrm{~K}$, there are four $\mathrm{Fe}^{3+}$ magnetic sublattices forming a canted type-G antiferromagnetic structure due to the Dzyaloshinsky-Moriya (D-M) interaction $^{[8-9]}$. As a result, rare-earth orthoferrites $\mathrm{ReFeO}_{3}$ possess a small total ferromagnetic moment $\mathrm{F}$ directed along $c$ axis, and an antiferromagnetic vector $\mathrm{G}$ along $a$ axis. The superexchange interaction involving the rare-earths ions are much weak, but they become noticeable at low temperature which is due to the superexchange interaction with $\mathrm{Fe}^{3+}$ neighbors. As temperature lowered, some of $\mathrm{ReFeO}_{3}$ possess two second order spin reorientation phase transition (SRT), at the vector $\mathrm{F}$ from the $c$ axis towards $a$ axis in a temperature range from $T_{\mathrm{SR} 2}$ to $T_{\mathrm{SR} 1}$ $\left(T_{\mathrm{SR} 1}<T_{\mathrm{SR} 2}<T_{\mathrm{N}}\right)$.

Among rare-earth orthoferrites, $\mathrm{SmFeO}_{3}$ has a maximum spin reorientation transition temperature $\left(T_{\mathrm{SR}} \approx\right.$ $480 \mathrm{~K})^{[2]}$. $\mathrm{SmFeO}_{3}$ has been recently reported to be ferroelectric at room temperature, which is matter of debate at the moment ${ }^{[2,10-11]}$.

It is known that orthoferrite solid solutions of a type $\mathrm{Re}_{1-x} \mathrm{Re}_{2 x} \mathrm{FeO}_{3}$ allow to tailor a number of their properties by varying the type and relative content of rare-earth ions ${ }^{[12]}$. Thus, $\mathrm{Sm}_{1-x} \mathrm{Re}_{2 x} \mathrm{FeO}_{3}$ solid solutions are the promising material for realizing a room-temperature functionality, including ultrafast laser-induced magnetization control, ferroelectricity, etc.

The optical-floating- zone growth is an excellent technique for this purpose, which is widely used to prepare the single crystal orthoferrites ${ }^{[13-20]}$. Many factors, such as stability of the molten zone, rotation rate of feed and seed rods, and the growth rate, during the growth progress, influenced the quality of an obtained single crystal. In the present work, high quality $\mathrm{Sm}_{0.8} \mathrm{~Tb}_{0.2} \mathrm{FeO}_{3}$ crystal was grown through optimized process and the structure, mag- 
netic and thermal properties of the crystal were investigated.

\section{Experimental details}

Polycrystalline samples $\mathrm{Sm}_{0.8} \mathrm{~Tb}_{0.2} \mathrm{FeO}_{3}$ were prepared by the conventional solid state reaction method, using the high purity oxide powder $\mathrm{Sm}_{2} \mathrm{O}_{3} \quad(99.99 \%), \quad \mathrm{Tb}_{4} \mathrm{O}_{7}$ (99.99\%) and $\mathrm{Fe}_{2} \mathrm{O}_{3}(99.99 \%)$ as the starting materials. The mixture was pressed into pellets and sintered in air at $1400 \mathrm{~K}$ for $20 \mathrm{~h}$. After confirmation by X-ray diffraction that the products had converted to the orthoferrite structure, the powder was then compacted into the rods, typically $5 \mathrm{~mm}$ in diameter and $50 \mathrm{~mm}$ long, using a hydraulic press under an isostatic pressure of $60 \mathrm{MPa}$. The rods were sintered in a vertical tube furnace at $1500 \mathrm{~K}$ for $15 \mathrm{~h}$ in air.

Single crystal growth was performed in the optical floating-zone furnace (FZ-T-10000-H-VI-P-SH, Crystal System Corp.). The parameters were at a growth rate of $1.5 \mathrm{~mm} / \mathrm{h}$ in flowing air $3 \mathrm{~L} / \mathrm{min}$ and rotation rate of feed and seed rods of $15 \mathrm{r} / \mathrm{min}$ in opposite directions. The polycrystalline samples were characterized by X-ray diffraction (XRD) using monochromatic $\mathrm{Cu} \mathrm{K} \alpha$ radiation. The room temperature XRD date were recorded for $15^{\circ} \leqslant$ $2 \theta \leqslant 90^{\circ}$ with a scanning step of $0.008^{\circ}$. Laue back reflection was used to examine the quality of crystals and to orient the crystals along the three principal axes. Magnetization measurement was carried out employing a VSM option on the Quantum Design physical property measurement system (PPMS-9, Quantum Design).

The thermal mechanical analyzer (Netzsch TMA $402 \mathrm{~F} 3$ ) was used to measure thermal expansion of the $\mathrm{Sm}_{0.8} \mathrm{~Tb}_{0.2} \mathrm{FeO}_{3}$ crystal with the dimensions of $3.34 \mathrm{~mm} \times$ $5.70 \mathrm{~mm} \times 2.60 \mathrm{~mm}$. The linear expansion coefficient of the single crystal was investigated at temperature range from $123 \mathrm{~K}$ to $1073 \mathrm{~K}$ at a heating rate of $5 \mathrm{~K} / \mathrm{min}$.

\section{Results and discussion}

The XRD pattern obtained at room temperature of the polycrystalline $\mathrm{Sm}_{0.8} \mathrm{~Tb}_{0.2} \mathrm{FeO}_{3}$ is presented in Fig. 1(b). All the peaks could be indexed to orthorhombic cell associated with space group Pbnm. It reveals the pure perovskite phase without phase impurity. The lattice parameters were estimated using powder diffraction data analysis software. The lattice parameters are $a=$ $0.5388(2) \mathrm{nm}, b=0.5602(8) \mathrm{nm}, c=0.7698(3) \mathrm{nm}$ which are a little smaller than that of $a=0.5398 \mathrm{~nm}, b=0.5598 \mathrm{~nm}$, $c=0.7709 \mathrm{~nm}$ of $\mathrm{SmFeO}_{3}$ (PDF-\#39-1490). This is because the ionic radius of $\mathrm{Tb}^{3+}$ is smaller than $\mathrm{Sm}^{3+}$. Laue
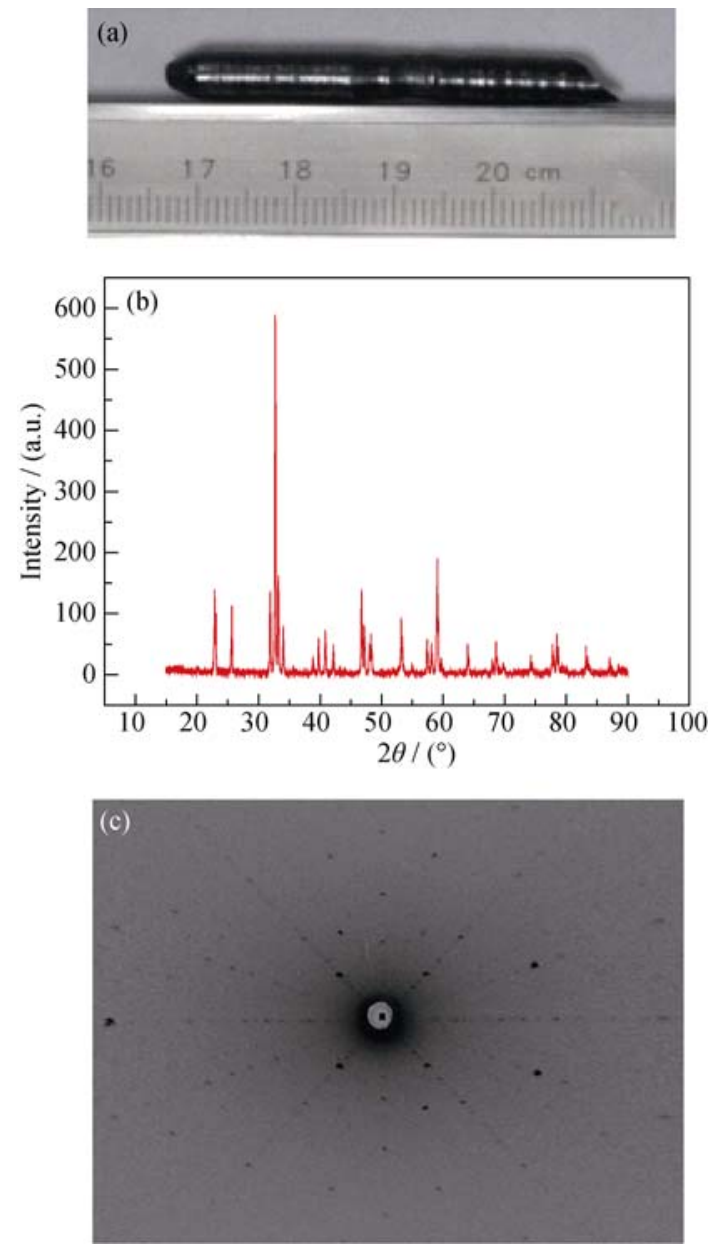

Fig. 1 (a) As-grown $\mathrm{Sm}_{0.8} \mathrm{~Tb}_{0.2} \mathrm{FeO}_{3}$ single crystal, (b) the powder XRD pattern of $\mathrm{Sm}_{0.8} \mathrm{~Tb}_{0.2} \mathrm{FeO}_{3}$ polycrystalline rod, and (c) the Laue back diffraction pattern of the $c$-direction plane cut from the as-grown single crystal

back diffraction pattern which is shown in Fig. 1 (c) confirmed the good quality of the grown $\mathrm{Sm}_{0.8} \mathrm{~Tb}_{0.2} \mathrm{FeO}_{3}$ single crystal.

Temperature dependence of magnetization $(M-T)$ of the $\mathrm{Sm}_{0.8} \mathrm{~Tb}_{0.2} \mathrm{FeO}_{3}$ single crystal under an applied field of 500 Oe along the $c$-axis at the temperature range from room temperature to $400 \mathrm{~K}$ is shown in Fig. 2. The temperature over $400 \mathrm{~K}$ was not investigated because of the limitation of the PPMS. A clear spin reorientation is observed through a temperature range from $360 \mathrm{~K}$ to $400 \mathrm{~K}$. The $\mathrm{Fe}^{3+}$ moments exhibit $\Gamma_{2}(\mathrm{~F} x, \mathrm{C} y, \mathrm{G} z)$ spin configuration at low temperature, accompanying with weak ferromagnetism along the $a$ axis. Upon heating temperature, the $\mathrm{Fe}^{3+}$ spins undergo a spin reorientation transition. At this transition, the spin configuration changes to $\Gamma_{4}(\mathrm{G} x, \mathrm{~A} y, \mathrm{~F} z)$.

The spin reorientation transition (SRT) temperatures of $\mathrm{Sm}_{1-x} \mathrm{~Tb}_{x} \mathrm{FeO}_{3}(x=0,0.2,0.3,0.45)^{[18,21-22]}$ are shown in Fig. 3. The spin reorientation transition temperature of $\mathrm{Sm}_{1-x} \mathrm{~Tb}_{x} \mathrm{FeO}_{3}$ is linear decreased with the increase of 


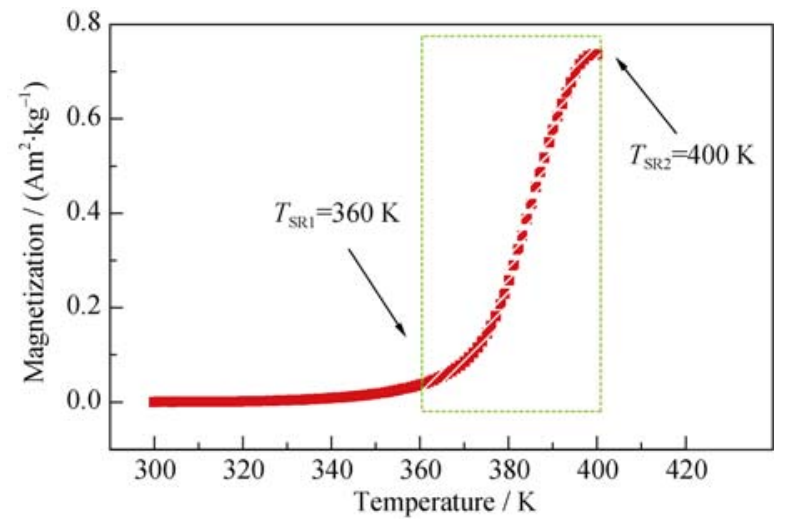

Fig. 2 Temperature dependence of the magnetization of $\mathrm{Sm}_{0.8} \mathrm{~Tb}_{0.2} \mathrm{FeO}_{3}$ single crystal measured in an external field $H=500$ Oe along $c$-axis

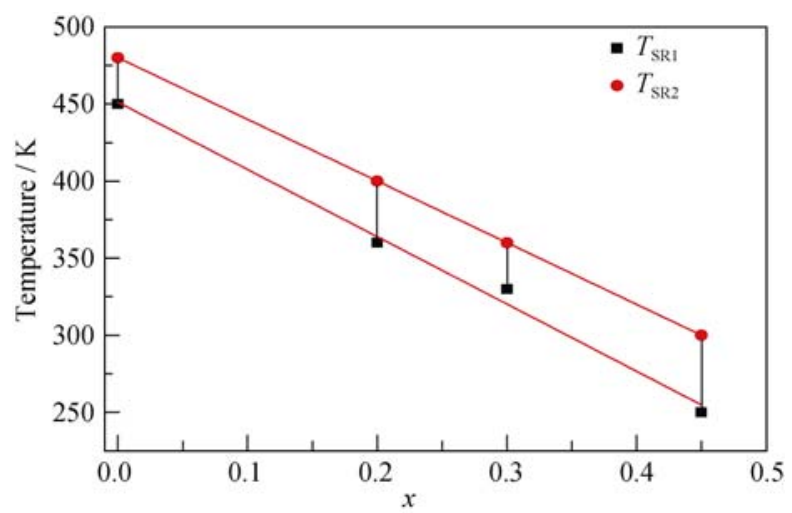

Fig. 3 Spin reorientation transition temperature of $\mathrm{Sm}_{1-x} \mathrm{~Tb}_{x} \mathrm{FeO}_{3}$ dependence of the doping content $x$. Data are from this work and from the literatures ${ }^{[18,21-22]}$

$\mathrm{Tb}$ ions content. The spin reorientation phase transitions in $\mathrm{ReFeO}_{3}$, which can be of the first as well as the second order, are driven by Fe-Re superexchange interactions ${ }^{[23]}$.

In Landau theory, symmetry of the lattice, the free energy of the spin system can be expanded in the order parameter $^{[24]}$ :

$$
F(\theta)=F_{0}+K_{2} \sin ^{2} \theta+K_{4} \sin ^{4} \theta
$$

Where $F_{0}$ is the isotropic free energy, $K_{2}$ is the second order anisotropy constant, $K_{4}$ is the fourth order anisotropy constant, and $\theta$ is the angle between the magnetization and the $c$ axis. Provided that the free energy function is analytic, one finds the following global minimum:

$$
\theta= \begin{cases}0 & \text { if } K_{2} \leqslant-2 K_{4} \\ \arcsin \sqrt{\frac{-K_{2}}{2 K_{4}}} & \text { if }-2 K_{4} \leqslant K_{2} \leqslant 0 \\ \frac{\pi}{2} & \text { if } K_{2} \geqslant 0\end{cases}
$$

As these equations show, the actual angle for which the free energy is minimal depends on the values of the anisotropy constants. Further understanding can be obtained by considering the microscopic mechanisms. The $\mathrm{Fe}^{3+}$ single ion anisotropy and the $\mathrm{Fe}^{3+}-\mathrm{Re}^{3+}$ antisymmetric superexchange interaction play the largest role in the spin reorientation transition ${ }^{[23]}$. While $\mathrm{Fe}^{3+}$ single ion anisotropy is mostly constant, antisymmetric superexchage shifts the crystal field split energy levels of the Re ions up and down by different amounts for the different configurations. The anisotropic exchange interactions between $\mathrm{Fe}^{3+}$ and rare-earth ions produce an effective field. As the temperature is lowered, this effective field increases due to the increase of the rare-earth magnetization, and when the interaction energy of the $\mathrm{Fe}^{3+}$ spins with these effective fields exceeds the anisotropy energy of the $\mathrm{Fe}^{3+}$ ion, spin reorientation takes place. Because the ions moment of $\mathrm{Tb}^{3+}$ is much larger than that of $\mathrm{Sm}^{3+}$ ion, the effective field increases with the increase of $\mathrm{Tb}$ ions content. The SRT temperature of high Tb-doped $\mathrm{SmFeO}_{3}$ is smaller than low Tb-doped $\mathrm{SmFeO}_{3}$, which is the result of the effective field in high $\mathrm{Tb}$-doped $\mathrm{SmFeO}_{3}$ exceeded the anisotropy energy of the $\mathrm{Fe}^{3+}$ ion at lower temperature.

The thermal expansion coefficient $\alpha$ corresponds to the slope of the linear thermal expansion:

$$
\alpha=\frac{\Delta L}{L_{0}} \frac{1}{\Delta T}
$$

Where $L_{0}$ is the original length of the crystal, $\Delta L$ is the change in length, and $\Delta T$ is the change in temperature. The vibration of the crystal lattice produces the thermal expansion when the crystal is heated.

Fig. 4 presents the temperature variation of the thermal expansion of $\mathrm{Sm}_{0.8} \mathrm{~Tb}_{0.2} \mathrm{FeO}_{3}$ crystal along $b$-direction in the temperature range of 128-973 K. The thermal expansion coefficient of $b$-direction increase from $3.0556 \times$ $10^{-6} \mathrm{~K}^{-1}$ to $7.2251 \times 10^{-6} \mathrm{~K}^{-1}$. The curve of temperature dependence of thermal expansion exhibits three phase transitions at about $250 \mathrm{~K}, 350-480 \mathrm{~K}$, and $700 \mathrm{~K}$, respectively. The iron spins transform from the antiferromagnetic ordered arrangement into paramagnetic disordered arrangement when heated at $T_{\mathrm{N}}\left(\mathrm{T}_{3}\right)$. The spin reorientation transition taken place through a temperature range from $350 \mathrm{~K}$ to $480 \mathrm{~K}\left(T_{2}\right)$, but the phase transition at $250 \mathrm{~K}$ $\left(T_{1}\right)$ has not yet been reported in rare earth doped $\mathrm{SmFeO}_{3}$. The transition taken place at about $250 \mathrm{~K}$ in rare-earth orthoferrite $\mathrm{TbFeO}_{3}$ was reported ${ }^{[25-26]}$. The abnormal transition in the temperature range of $200-300 \mathrm{~K}$ is considered to be related to the spin reorientation ${ }^{[26]}$, but the spin reorientation transition temperature of $\mathrm{TbFeO}_{3}$ is about $20 \mathrm{~K}^{[27]}$. The rare-earth magnetic moments align parallel or antiparallel to the net iron magnetic moment which polarized by $\mathrm{Fe}^{3+}$ sub-lattice net moment at low temperature. The anomaly observed at $250 \mathrm{~K}$ may be result of the change of rare earth ions moment orientation. The rare-earth magnetic moments align antiparallel to the 


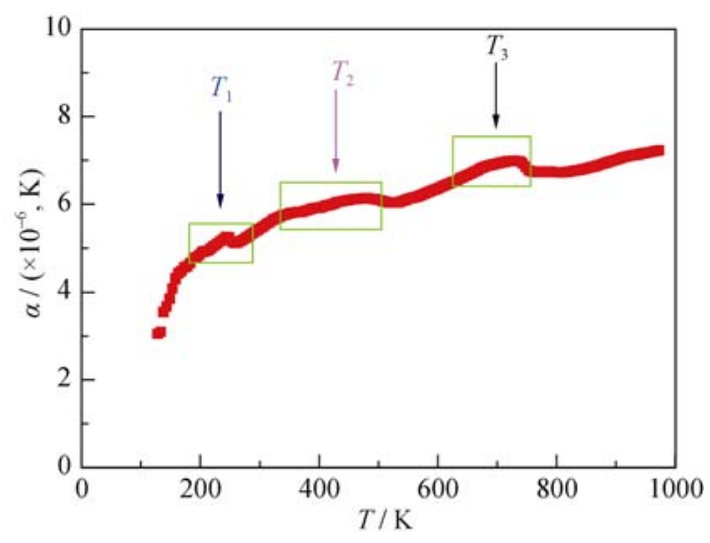

Fig. 4 Temperature dependence of thermal expansion along $b$-direction

net iron magnetic moment under $\mathrm{Fe}^{3+}$ spin reorientation transition temperature in $\mathrm{SmFeO}_{3}{ }^{[21]}$, but parallel to the net iron magnetic moment at low temperature in $\mathrm{Sm}_{1-x} \mathrm{~Tb}_{x} \mathrm{FeO}_{3}{ }^{[18]}$. The temperature range of $\mathrm{Fe}^{3+}$ spin reorientation measured by TMA is a little higher than that by PPMS, which may be the result of response time of the method.

\section{Conclusions}

$\mathrm{Sm}_{0.8} \mathrm{~Tb}_{0.2} \mathrm{FeO}_{3}$ single crystal has been successfully grown by the optical floating zone method. Laue back reflection was used to examine the quality of crystals and to orient the crystals along the three principal axes. A spin reorientation behavior with the transition of the $\mathrm{Fe}^{3+}$ magnetic moment ordering from $\Gamma_{2}(\mathrm{~F} x, \mathrm{C} y, \mathrm{Gz})$ to $\Gamma_{4}(\mathrm{G} x, \mathrm{~A} y, \mathrm{~F} z)$ is observed in a range of $360-400 \mathrm{~K}$. The anisotropic exchange interactions between $\mathrm{Fe}^{3+}$ and rare-earth ions produce an effective field. Because the ions moment of $\mathrm{Tb}^{3+}$ is much larger than $\mathrm{Sm}^{3+}$ ion, the effective field increasing with the increase of $\mathrm{Tb}$ ions content. The spin reorientation transition temperature of $\mathrm{Sm}_{1-x} \mathrm{~Tb}_{x} \mathrm{FeO}_{3}$ is linear decreasing with the increase of $\mathrm{Tb}$ ions content.

The mean thermal expansion coefficients along $b$-direction increase with increasing temperature. And the thermal expansion measured indicates $\mathrm{Sm}_{0.8} \mathrm{~Tb}_{0.2} \mathrm{FeO}_{3}$ has three phase transitions at about $250 \mathrm{~K}, 350-480 \mathrm{~K}$, and $700 \mathrm{~K}$, respectively. The iron spins transform from the antiferromagnetic ordered arrangement into paramagnetic disordered arrangement when heated at $\sim 700 \mathrm{~K}$. The spin reorientation transition taken place through a temperature range from 350 to $480 \mathrm{~K}$. The anomaly observed at $250 \mathrm{~K}$ may result from the change of rare earth ions moment orientation polarized by $\mathrm{Fe}^{3+}$ sub-lattice net moment.

\section{References:}

[1] WHITE R L. Review of recent work on the magnetic and spectroscopic properties of the rare-earth orthoferrites. Journal of Applied Physics, 1969, 40: 1061-1069.

[2] LEE J H, JEONG Y K, PARK J H, et al. Spin-canting-induced improper ferroelectricity and spontaneous magnetization reversal in $\mathrm{SmFeO}_{3}$. Physical Review Letters, 2011, 107(11): 117201-1-5.

[3] TOKUNAGA Y, IGUCHI S, ARIMA T, et al. Magnetic-field- induced ferroelectric state in $\mathrm{DyFeO}_{3}$. Physical Review Letters, 2008, 101(9): 097205-1-4.

[4] TOKUNAGA Y, FURUKAWA N, SAKAI H, et al. Composite domain walls in a multiferroic perovskite ferrite. Nature Materials, 2009, 8(7): 558-562.

[5] TOKUNAGA Y, TAGUCHI Y, ARIMA T, et al. Magnetic biasing of a ferroelectric hysteresis loop in a multiferroic orthoferrite. Physical Review Letters, 2014, 112(3): 037203-1-5.

[6] KIMEL A V, KIRILYUK A, USACHEV P A, et al. Ultrafast nonthermal control of magnetization by instantaneous photomagnetic pulse. Nature, 2005, 435(7042): 655-657.

[7] KIMEL A V, IVANOV B A, PISAREV R V, et al. Inertia-driven spin switching in antiferromagnets. Nature Physics, 2009, 5(10): $727-731$.

[8] DZYALOSHINSKY I. A thermodynamic theory of weak ferromagnetism antiferromagnetics. Journal of Physics and Chemistry of Solids, 1958, 4(4): 241-255.

[9] MORIYA T. Anisotropic superexchange interaction and weak ferromagnetism. Physical Review, 1960, 120(1): 91-98.

[10] BOSSINI D, MALIK D, REDLICH B, et al. Time-resolved nonlinear infrared spectroscopy of samarium ions in $\mathrm{SmFeO}_{3}$. Physical Review B, 2013, 87(8): 085101-1-4.

[11] KUO C Y, DREES Y, FERNÁNDEZ-DÍAZ M T, et al. $k=0$ magnetic structure and absence of ferroelectricity in $\mathrm{SmFeO}_{3}$. Physical Review Letters, 2014, 113(21): 217203-1-5.

[12] SHERWOOD R C, VAN UITERT L G, WOLFE R, et al. Varition of the reorientation temperature and magnetic crystal anisotropy of the rare-earth orthoferrites. Physical Letters A, 1967, 25(4): 297-298.

[13] SHEN HUI, XU JUN, WU AN-HUA, et al. Growth and characterization of magneto-optical $\mathrm{YFeO}_{3}$ crystals. Crystal Research and Technology, 2007, 42(10): 943-947.

[14] WANG YAN-BIN, CAO SHI-XUN, SHAO MING-JIE, et al. Growth rate dependence of the $\mathrm{NdFeO}_{3}$ single crystal grown by float-zone technique. Journal of Crystal Growth, 2011, 318(1): 927-931.

[15] CHANG FEN-FEN, YUAN SHU-JUAN, WANG YAN-BIN, et 
al. Growth and surface morphology of $\mathrm{ErFeO}_{3}$ single crystal. Journal of Crystal Growth, 2011, 318(1): 932-935.

[16] SHAO MING-JIE, CAO SHI-XUN, WANG YAN-BIN, et al. Large magnetocaloric effect in $\mathrm{HoFeO}_{3}$ single crystal. Solid State Communications, 2012, 152(11): 947-950.

[17] WU AN-HUA, SHEN HUI, XU JUN, et al. Crystal growth and magnetic property of $\mathrm{YFeO}_{3}$ crystal. Bulletin of Materials Science, 2012, 35(2): 259-263.

[18] WANG BO, ZHAO XIANG-YANG, WU AN-HUA, et al. Single crystal growth and magnetic properties of $\mathrm{Sm}_{0.7} \mathrm{~Tb}_{0.3} \mathrm{FeO}_{3}$ orthoferrite single crystal. Journal of Magnetism and Magnetic Materials, 2015, 379: 192-195.

[19] WU AN-HUA, WANG ZHAN-LIANG, WANG BO, et al. Crystal growth and magnetic properties of $\mathrm{GdFeO}_{3}$ crystals by floating zone method. Solid State Communications, 2014, 185: 14-17.

[20] WANG XIN-YAN, CAO SHI-XUN, WANG YAN-BIN, et $a l$. Crystal growth and characterization of the rare earth orthoferrite $\mathrm{PrFeO}_{3}$. Journal of Crystal Growth, 2013, 362: 216-219.

[21] CAO SHI-XUN, ZHAO HNA-ZHI, KANG BAO-JUAN, et al. Temperature induced spin switching in $\mathrm{SmFeO}_{3}$ single crystal. Scientific Reports, 2014, 4: 5960-1-5.

[22] KOCHARYAN K N, MARTIROSYAN R M, KARNEEVA S S, et al. Anisotropy in the susceptibility of $\mathrm{Sm}_{0.55} \mathrm{~Tb}_{0.45} \mathrm{FeO}_{3}$ orthoferrite. Fizika Tverdogo Tela, 1987, 29(3): 924-925.

[23] YAMAGUCHI T. Theory of spin reorientation in rare-earth orthochromites and orthoferrites. Journal of Physics and Chemistry of Solids, 1974, 35(4): 479-500.

[24] HORNER H, VARMA C M. Nature of spin-reorientation transitions. Physical Review Letters, 1968, 16(20): 845-846.

[25] KIM S B, MOON S J, KIM S J, et al. Extraordinary magnetic behavior in $\mathrm{TbFeO}_{3}$. Journal of Magnetism and Magnetic Materials, 2007, 310(2): 592-594.

[26] ZOU Y H, LI W L, WANG S L, et al. Spin dependent electrical abnormal in $\mathrm{TbFeO}_{3}$. Journal of Alloys and Compounds, 2012, 519: $82-84$.

[27] PARK B G, KIM S B, LEE H J, et al. Magnetic properties of the orthoferrites $\mathrm{TbFeO}_{3}$ and $\mathrm{ErFeO}_{3}$. Journal of the Korean Physical Society, 2008, 53(2): 758-762.

\title{
稀土正铁氧体 $\mathrm{Sm}_{0.8} \mathrm{~Tb}_{0.2} \mathrm{FeO}_{3}$ 单晶的生长及性能
}

\author{
赵向阳 ${ }^{1}$ ，满沛文 ${ }^{1}$, 谢 涛 $^{2}$, 武安华 ${ }^{1}$ ，苏良碧 ${ }^{1}$ \\ (1. 中国科学院 上海硅酸盐研究所, 上海 $200050 ; 2$. 上海应用技术学院, 上海 200235)
}

\begin{abstract}
摘 要: 利用光学浮区法生长 $\mathrm{Sm}_{0.8} \mathrm{~Tb}_{0.2} \mathrm{FeO}_{3}$ 单晶, 采用劳尔背衍射仪对样品质量进行检测并定向。测试了 $c$-切 $\mathrm{Sm}_{0.8} \mathrm{~Tb}_{0.2} \mathrm{FeO}_{3}$ 单晶在零场冷却模式的磁温曲线, 发现其自旋重取向温度范围为 $360 \sim 400 \mathrm{~K}$ 。总结以前的工作发现 $\mathrm{Sm}_{1-x} \mathrm{~Tb}_{x} \mathrm{FeO}_{3}$ 系列材料的自旋重取向温度随着稀土琙( $\mathrm{Tb}$ )含量的增加而线性减小, 这表明 $\mathrm{Sm}_{1-x} \mathrm{~Tb}_{x} \mathrm{FeO}_{3}$ 系列材料中 $\mathrm{Fe}^{3+}-\mathrm{Re}^{3+}$ 之间的超交换作用发生变化。热膨胀测试结果发现 $\mathrm{Sm}_{0.8} \mathrm{~Tb}_{0.2} \mathrm{FeO}_{3}$ 存在三个温度转变区域: $250 \mathrm{~K}$ 、 $350 \sim 480 \mathrm{~K}$ 和 $700 \mathrm{~K} 。 250 \mathrm{~K}$ 发生的不正常相变是由于铁离子弱铁磁矩诱导的稀土离子磁矩方向的改变造成的, $350 \sim 480 \mathrm{~K}$ 是由于在这一温度范围发生铁离子自旋重取向，而 $700 \mathrm{~K}$ 发生的相变是由于铁离子自旋由反铁磁有序到 顺磁无序的磁转变。
\end{abstract}

关 键 词: 正铁氧体; 光学浮区法; 相转变

中图分类号: TQ174

文献标识码: A 